\title{
Socio-economic and spatial determinants of municipal cultural spending
}

\author{
Michael Getzner ${ }^{1}$ (D)
}

Received: 30 November 2020 / Accepted: 26 October 2021 / Published online: 7 November 2021

(c) The Author(s) 2021

\begin{abstract}
The determinants of the expenditure of Austrian municipalities for cultural affairs are ascertained in a panel time series framework. The Austrian municipalities spend about $€ 93$ per capita a year for cultural affairs (approximately $4 \%$ of the total municipal expenditure). The econometric estimations revealed that the size of the municipality, and various socio-economic, fiscal and political variables, are the main determinants of municipal cultural spending. The results of the estimations infer a rather small but nevertheless significant spatial dependence of cultural spending. An increase of $10 \%$ of cultural spending in the neighboring regions leads to an increase of $0.6-1.5 \%$ in a representative municipality (however, the potentially overlapping and contradicting reasons for spatial correlations could not be disentangled in this paper). In comparison to the spatial effects, the size of the municipality is a more significant predictor of municipal cultural spending. The larger cities provide many cultural goods and services to the surrounding areas by utilizing economies of scale and density. It can be concluded that municipalities, in particular in rural areas, should increase their efforts for co-operation in order to improve the efficiency of cultural spending.
\end{abstract}

Keywords Municipal expenditure for cultural purposes - The determinants of spending $\cdot$ Spatial correlation $\cdot$ Austria

\section{Introduction and background}

Austrian municipalities spend about $€ 93$ per capita a year for cultural affairs. This amounts to about $4 \%$ of the total municipal expenditure. Owing to the federal system of Austria, the national and the provincial (regional) governments also have their stakes in cultural policies, through annual expenditures of about $€ 95$ and $€ 105$ per

Michael Getzner

michael.getzner@tuwien.ac.at

1 Department of Public Finance and Infrastructure Policy, Institute of Spatial Planning, Vienna University of Technology (TU Wien), Karlsplatz 13, 1040 Vienna, Austria 
capita, respectively (data from Statistics Austria, 2020). Compared to other (European) countries, the public cultural spending in Austria is substantial and aboveaverage both in absolute as well as relative terms (Compendium, 2021; see Sect. 3 of this paper). It is therefore of great interest to investigate the determinants of public cultural spending, and to discuss how these expenditures relate to socio-economic, budgetary, political and spatial variables.

In order to place this paper in the cultural policy framework of a federal state, it is, first of all, important to clarify the role of municipalities in cultural policies. The design and implementation of cultural policies fall into the authority of each of the different levels of government. The Austrian constitution does not provide for precise regulations in regard to cultural policies (Getzner \& Bröthaler, 2019; Zembylas \& Mokre, 2003). Generally, cultural policies fall under the category of 'voluntary' public tasks of municipalities, contrary to the mandatory (statutory) or strictly regulated municipal infrastructures and services. However, there are federal laws for conserving cultural heritage and managing national museums and theaters. Provincial laws regulate, for instance, the organization, provision and funding of Schools of Music. In fact, it has been argued that cultural policies are one of the few areas in which municipalities have a significant freedom in making local decisions (Schulze \& Rose, 1998). Theories of federalism, cultural policies and economics generally infer that these different levels of government may fulfill specific functions and roles in cultural policies. 'Cultural policy' is understood in this paper as a municipal policy field dealing with cultural institutions (Hasitschka, 2018; Zembylas, 2004). Besides institutions of the performing and fine arts, Hasitschka (2018) included the fields of education, research, media, religion, and legal systems, in his definition of cultural institutions. Tröndle and Steigerwald (2019) follow a more pragmatic approach by focusing on the concept of cultural policy in a narrow analytical framework. They account for cultural policies in the sense of dealing with the legal regulations of producing and distributing artistic products, such as copyright law, constitutional rights (freedom of artistic expression), as well as cultural institutions confined to the arts and typically considered as such (theaters, museums, art shows, concert halls). In this paper, a narrow approach to cultural policies in the latter sense is chosen.

While there is no legal obligation to spend for cultural affairs as these are 'voluntary' municipal tasks, municipalities operate, of course, cultural institutions, often support cultural activities, fund local art associations and manage cultural centers for live events, such as concerts and art exhibitions. Given the argument that municipal decision-makers are 'close to the citizens' (e.g., Benito et al., 2013), it may be hypothesized that municipal cultural spending may be more in line with the citizens' cultural preferences. Municipal cultural spending is eventually also more susceptible to political cycles. However, scholars have stressed the importance of a wide range of determinants of cultural spending, such as socio-economic, fiscal, political and spatial variables (e.g., López et al., 2017).

In this paper, the determinants of the cultural spending of Austrian municipalities are investigated within a panel time series framework. While the approach accounts for the socio-economic variables that are commonly used, in regard to education, age and the income of citizens, the paper extends the standard frameworks by spatial 
determinants, such as the type of municipality (urban vs. rural), the size of the municipality, as well as the spatial distribution of the expenditures. The latter aspect is studied by using several spatial econometric models.

Against this background, the following research questions guide the empirical work of this paper:

- How do socio-economic variables, such as the average income, age, and education of residents, correlate with municipal cultural spending?

- To what extent does cultural spending depend on the financial situation of the municipality?

- Which spatial variables, such as the size of the municipality, and the location (urban vs. rural), influence municipal spending?

- Is cultural spending of neighboring municipalities correlated?

By answering these research questions, the paper is intended to contribute to the growing empirical literature in which the various hypotheses and concepts of cultural economics, cultural sociology and cultural studies are tested (e.g., on the differences between urban and rural populations, and on the socio-economic determinants of cultural policies). Based on the research questions outlined above, and on the detailed literature review of potential determinants of municipal cultural spending in Sect. 2, this paper empirically tests the following hypotheses. Firstly, it is hypothesized that the size of the municipality matters; cities and larger municipalities are assumed to provide cultural infrastructures not only to their own citizens but to the surrounding regions, and therefore face higher per-capita cultural spending. Secondly, the socio-economic composition of the municipal population influences cultural spending significantly. Based on the available evidence on cultural consumption, it is hypothesized that cultural spending increases with average income, age and education of the electorate. Thirdly, it is hypothesized that cultural spending depends on the municipality's fiscal position. Cultural expenditure increases with the financial resources of the municipality (own taxes, total expenditure, cash-flow), but is reduced in times of fiscal stress (denoted by municipal debt). Finally, cultural spending is supposed to be influenced by the party affiliation of the mayor (and the majority of the representatives in the respective municipal councils). It is hypothesized that conservative mayors spend more on culture than social-democrats.

In regard to the spatial correlation of the municipal spending of neighboring municipalities, it is hypothesized that there is a strong correlation between cultural spending.

The novelty of this paper lies in the use of a huge dataset on municipal cultural spending (about 2100 Austrian municipalities over a period from 2004 to 2018), and on a distance matrix that includes all spatial relationships between Austrian municipalities. Furthermore, this paper draws on a recent study on the cultural participation and cultural consumption of Austrian citizens (Getzner, 2020a). From this study, there is detailed information available about the average distance traveled to cultural events. The neighborhood of municipalities is empirically defined by a radius (distance) of 15-30 min (details are provided below), resulting in a respective weighting matrix for the spatial regressions presented in this paper. 
The structure of the paper is as follows: A brief literature review on the empirical evidence of the potential determinants of municipal cultural spending is presented in Sect. 2. The methods and data sources are described in Sect. 3. The descriptive and econometric results are discussed in Sects. 4 and 5, while in Sect. 6, the results are summarized and conclusions are drawn.

\section{The determinants of municipal cultural spending: a brief overview}

In general, municipal fiscal policies depend on a wide range of legal, socio-economic, political and spatial frameworks. Many papers investigating municipal spending (and debt) basically draw on Wagner's law of increasing state activities, assuming that the income of households, and the revenues of the municipality itself (by taxation or revenues from utility fees), are positively correlated with the spending of the municipality. This correlation reflects on a positive elasticity of expenditures in relation to income, which might be even larger than unity (see Wagner, 1958; referring to local/regional spending: e.g., Batisda et al., 2013; Gebremariam et al., 2012). In regard to cultural policies, the arguments in favor of state intervention are based on market failures, but also include the pros and cons of public spending in general (e.g., Frey, 1999), such as the political economy of budgetary policies. The empirical evidence on the validity of Wagner's law is certainly mixed (Peacock \& Scott, 2000), but serves as a good starting point for the empirical analyses, especially in combination with other socio-economic variables, such as the levels and changes of age and education of the electorate over a period of time (cf. Feder \& Katz-Gerro, 2012; Rössel \& Weingartner, 2015). ${ }^{1}$

In addition, the size of the municipality matters (e.g., Costa et al., 2015), since larger municipalities may provide cultural infrastructure to the surrounding regions (for Austria, see e.g., Mitterer et al., 2016). Furthermore, the cultural infrastructure of cities may spillover to the smaller municipalities, which might in turn try to freeride (see below for a more in-depth discussion on spatial interdependencies). In regard to cultural spending, the support for cultural institutions and the frequency of visits to cultural events usually depend on these variables (Seaman, 2006; Kirchberg \& Kuchar, 2014; recently for Austria: Getzner, 2020b). While the size of the municipality may also be congruent with the urban-rural classification (see Sect. 3 for details), some municipalities may also face above-average cultural spending owing to their specific economic structure. The municipalities with a high share of tourism may provide cultural goods and services not only to their residents, but can also try to improve their region as an attractive tourist destination (cf. Richards, 2018).

Furthermore, the political economy of budgetary policies might be very pronounced at the local levels of government, since the municipal decision-makers are in direct contact with the citizens, and may be better informed about their voters' preferences on cultural spending (Benito et al, 2013). It can therefore be argued that

\footnotetext{
1 This paper therefore differs from studies on the effects of (municipal) cultural expenditure on the cultural capital of a society, or on the 'cultural atmosphere' (Cheng, 2006).
} 
mayors and municipal councils represent the preferences of their electorate more closely in the fields of local public policies and services. Sanjuán et al. (2020) present a case for Spanish medium-sized cities where a clear political business cycle can be observed for municipal cultural spending. For the Spanish case, the authors argue that municipal decision makers can increase their chance of re-election substantially if they expand cultural spending before the respective elections (cf. Benito et al., 2013). However, politico-economic variables, such as the ideology of the ruling party, and the relation between majority and minority parties, might not be as relevant as on the national or provincial level (in regard to municipal cultural spending in Italy, see Dalle Nogare \& Galizzi, 2011; cf. Potrafke, 2011). Scholars argued that voters cast their ballots differently in national, regional and local polls. However, this viewpoint has recently been challenged (cf. Lucas \& McGregor, 2020). In regard to the fiscal policies of Austrian municipalities, Bröthaler et al. (2015) concluded that municipalities are constrained in their ability to issue municipal debt, and that politico-economic variables have little, if any, influence on municipal debt. There is currently no study available that tests the political business cycle hypothesis for Austrian municipal cultural spending.

Finally, municipal fiscal policies both depend on several (constitutional) frameworks that constrain budgetary policies in terms of debt issuance or taxation, and on spatial interdependence.

On the one hand, the degree of decentralization and/or autonomy in setting tax rates or issuing debt is diverse between the countries with a federal system. ${ }^{2}$ The leeway of municipal taxation and pricing utilities (by means of utility fees) is rather limited for municipalities in Austria. On average, only about 5\% of the municipal revenues are decided autonomously, while another $20 \%$ of the revenues can be determined within certain limits (cf. Bröthaler \& Getzner, 2011). The cultural spending of municipalities is particularly sensitive to the financial resources of the municipalities since, for instance, subsidies might easily be reduced in times of fiscal stress. Municipal debt as well as the 'cash flow' (free financial resources) of municipalities has proven to have significant influence on cultural spending (e.g., Noonan, 2015; Schulze \& Rose, 1998).

In regard to the Austrian cultural policy context, public cultural expenditures have been studied on the levels of national and regional (provincial) governments. Getzner (2015) came to the conclusion that the cultural spending of the Austrian national government gradually stabilized in accordance with economic growth, and inferred that the cultural goods and services provided by the national government are 'normal' goods in regard to income (GDP per capita). The political factors (i.e., political business cycles) did not significantly influence the level of public cultural spending, but there was a small negative correlation between national and regional (provincial) cultural spending. This result infers that the reduction of provincial spending was offset by an increase of national spending, and vice versa. Regional

\footnotetext{
2 While setting tax rates on the local level is also limited in other countries, Buettner and Janeba (2016) discuss the positive effects of municipal funding of local cultural infrastructures on the choices for locations of production made by companies.
} 
(provincial) cultural spending in Austria was studied by Getzner (2004). Data from the nine federal provinces were analyzed in a panel setting. The results indicate that the provincial cultural spending was closely correlated with the gross regional product and was not determined by political variables, such as the ideology of the ruling party, even when considering the various political circumstances in each of the provinces.

On the other hand, spatial interdependence is considered to be one of the major influential factors of municipal spending (cf. Case \& Rosen, 1993). The possible reasons for inter-municipal dependence are manifold. In the following, the diverse factors of spatial relations of municipal (cultural) spending will briefly be discussed. However, it has to be noted that based on the available data, this paper cannot disentangle the various reasons for such interdependencies:

- From the perspective of providing a regional infrastructure, the money spent by municipality $A$ might 'spillover' to municipality $B$. Examples include the spending for cultural venues (e.g., López et al., 2017), such as theaters and Schools of Music, or public swimming pools and other recreational facilities. Owing to potential economies of scale, scope and density, and a more favorable spatial location, many of these facilities are located in larger and/or central municipalities, which are easily accessible for many citizens in the surrounding regions. From the perspective of efficiency, the costs per user are reduced. Municipalities may function as regional centers or 'central places' providing public services and public goods as well as infrastructures to the whole region (Mitterer et al., 2016; Werck et al., 2008). As briefly discussed before, the size of the municipality and the spatial correlation between cultural spending might therefore be important predictors of municipal cultural spending. In a French study, co-operation between the municipalities, in a certain region, has not been found to reduce municipal spending, but potential spillover effects between municipalities are internalized through co-operative agreements (Frère et al., 2014).

- The municipal spending of municipality $A$ might also depend on the one by municipality $B$ if $A$ tries to free-ride on regional public goods that $B$ provides.

- The citizens of municipality $A$ might also observe the spending and provision of public services of municipality $B$, and therefore compare the efficiency of the provision of infrastructures in their own town with neighboring communities (yardstick competition, mimicking). Thus, the spending of $A$ and $B$ might be positively correlated also in a situation of non-co-operative behavior. Štàstná (2009) found a positive spatial correlation of cultural spending in Czech municipalities owing to mimicking behavior of neighboring municipalities. Di Liddo and Giuranno (2016) discussed the various economic and political implications in a scenario of yardstick competition and co-operation.

- The municipality $A$ might also consider municipality $B$ 's spending in its own spending decisions, in the sense of providing regional services other than those provided by municipality $B$. Lundberg (2006) analyzed 'strategic substitutes' between municipalities in the fields of recreational and cultural services. The decision-makers of $A$ might also consider 'inter-municipal solidarity' in a tit-for-tat game. If $B$ provides some regional infrastructure 
(or regional public goods), $A$ might follow with an offer for another kind of regional infrastructure (and v.v.) (cf. Bel \& Warner, 2015).

- The municipalities $A$ and $B$ may also co-operate, which is quite common in certain areas of the provision of infrastructure, such as water, sewage and waste management. Furthermore, a large variety of different forms of intermunicipal co-operation exists, based on the economies of scale and scope. In addition, the regional development programs are designed and implemented, in Austria, on the level of districts or federal provinces (states). Such programs include the planning of commercial districts (e.g., industrial sites, shopping centers) and broad functional focuses (e.g., municipalities devoted largely to residential areas, tourism or recreation).

- The spending of municipalities $A$ and $B$ might also be correlated owing to different (or similar) determinants of their respective spending, such as population growth and economic structure (e.g., López et al., 2017), without any causal linkages between the spending categories.

- Finally, in a model of the spending of the two municipalities, $A$ and $B$, their spending may not only function as an explanatory variable of A's spending, but also that the error terms might as well be correlated.

In regard to the topic of this paper, the cultural spending of Austrian municipalities, there may be a number of different explanations for a potential spatial correlation of the neighboring municipalities' policies. It is important to note that cultural expenditures-as mentioned before-are often non-compulsory (non-statutory) categories of spending (that does not mean, however, that they are not important to citizens) (Benito et al., 2013). From a methodological point of view, there are numerous approaches of spatial econometrics that can estimate the relevance of the arguments mentioned above. However, a choice had to be made in regard to the research questions of this paper, and the availability of data for the analysis.

In regard to the arguments briefly summarized here, it is unclear how spatial correlations affect the cultural expenditure of a certain municipality. For instance, if yardstick competition is prevalent, the cultural spending of neighboring municipalities might be positively correlated. If a certain municipality wants to free-ride, or specialize in a certain regional infrastructure while reducing its cultural spending, the spatial correlation might be negative. The size and direction of the spatial correlation of the municipal cultural spending can, in the end, be determined only empirically. However, testing the spatial correlations empirically points to a further complication. The arguments made above in regard to positive and negative spatial correlation of municipal spending might be present at the same time, and therefore be mixed up. As will be discussed below, this paper lacks the empirical approach and data to differentiate between the causes and direction of potential spatial correlation, but nevertheless presents evidence for the 'net' spatial correlation of municipal spending. 


\section{Methods and data}

This paper is based on a comprehensive database of public finances in Austria (Gembon, 2019; Statistics Austria, 2020). This database includes all public budgets (federal, provincial and municipal budgets). Complete and consistent data on cultural spending and other indicators of municipal fiscal policies, such as municipal debt, total spending and revenues, are available for the period of 2004-2018. The official budgetary statistics record the municipal revenues and spending. If a municipality decides to provide some cultural infrastructure in an out-sourced organization, only the net balance as flows from/to the organization (e.g., covering of the losses of the local out-sourced theater) is recorded (cf. Bertacchini \& Dalle Nogare, 2014). However, the out-sourcing of public services is an important budgetary policy in the fields of water, sewage, and waste management for municipalities in Austria, but less so in the fields of cultural policies.

In addition to the public finance variables, a range of socio-economic variables are included in the analysis of this paper, which were retrieved from the demographic databases of Statistics Austria (2020). These data include the total population, the average income of households, the education and the age of the population.

In order to classify the Austrian municipalities, this paper uses the urban-rural typology published by Statistics Austria. This typology classifies municipalities in 11 categories ranging from large cities ( $>50,000$ residents) to small rural and peripheral municipalities. The other categories are, e.g., regional centers, rural towns close to metropolitan areas, and smaller cities (Fig. 2 presents details on municipal spending according to the categories of the urban-rural typology). For the descriptive analysis presented in Sect. 4, the 11 categories are aggregated to the three broad categories 'urban,' 'intermediate,' and 'rural.' In addition, all municipalities are classified according to the importance of tourism for the local economy (dichotomous variable) (for a description of all variables used in the analyses, see Table 1; this table also includes some descriptive statistics of all variables).

In order to account for a potential spatial correlation, the estimations of this paper are based on a spatial weighting matrix. The underlying matrix includes the data on the travel distance from the center of each municipality to all other municipalities, both in kilometers and in minutes (by car; see Lundberg, 2006). Defining the spatial proximity and neighborhood of municipalities is always crucial (and tricky) in spatial econometrics. However, given the Austrian Alpine typography, it is not reasonable to define neighboring municipalities by a common border but by accessibility measured by travel time. In regard to cultural events, Getzner (2020a) studied the frequency of visits to cultural events, and travel distances, and found that households travel from around $15 \mathrm{~min}$ to local cultural venues (e.g., cinemas, libraries, Schools of Music) up to about $30 \mathrm{~min}$ (e.g., theaters, museums). Opera houses are the furthest away. Citizens travel up to $45 \mathrm{~min}$ to get there. The distance of travel is therefore a crucial factor for using cultural institutions. Given the empirical data, it is reasonable to define a cut-off 


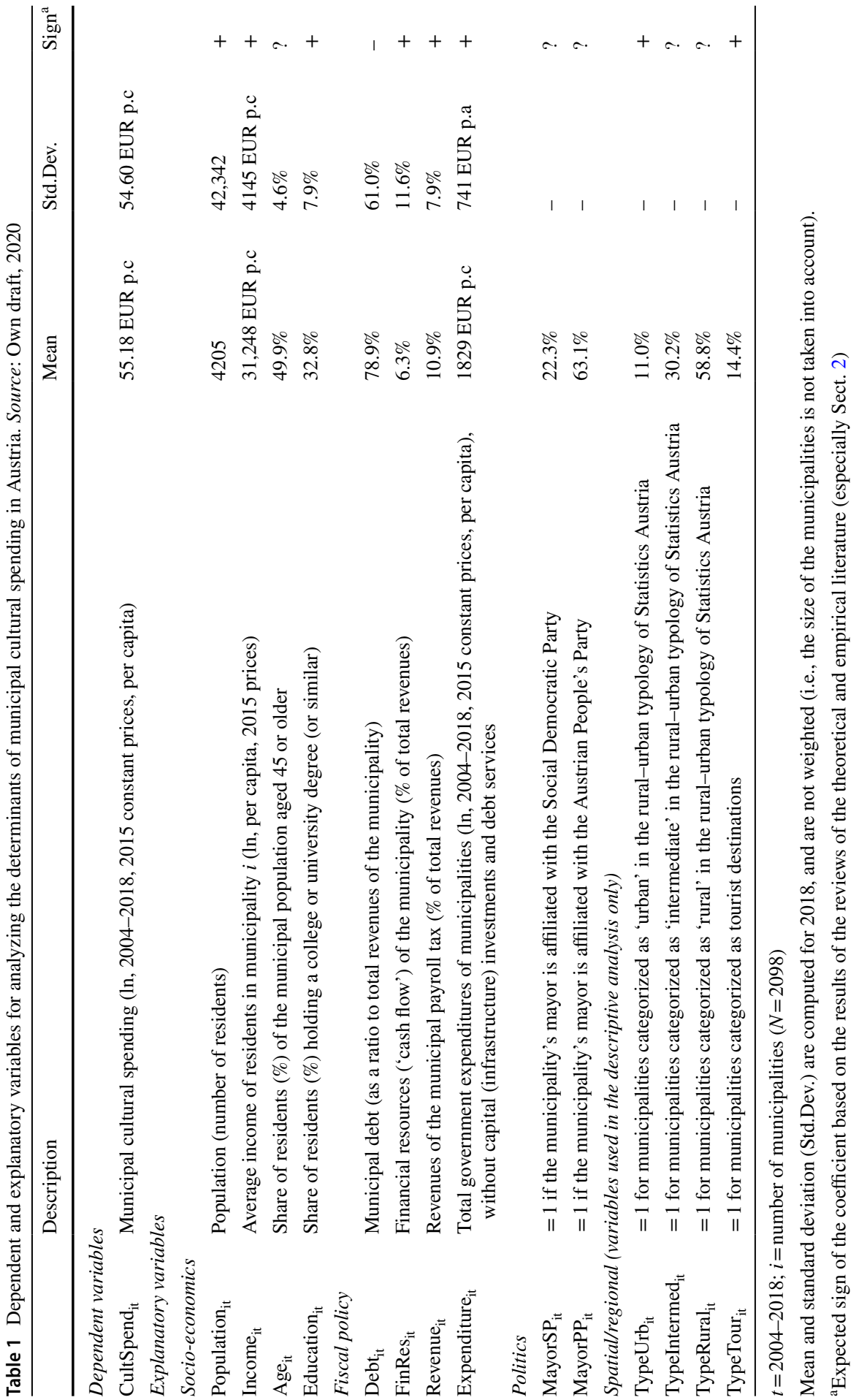


point at $45 \mathrm{~min}$ of the distance of travel at the most, and to weigh cultural spending of neighboring municipalities inversely proportional to the distance. In order to account for spatial auto-regression, different weight matrices are used with cutoff distances of 15 and $30 \mathrm{~min}$ in the econometric estimations (within the chosen distance, cultural spending of neighboring municipalities are weighted inversely proportional). ${ }^{3}$

In regard to political variables, a separate database was set up to record the shares of political parties in the last municipal election and the party affiliation of the mayors by collecting the scattered results from the governments of each federal province. The party affiliation of the mayors is finally used in this paper to account for majorities in the respective municipal councils as in most cases, the mayors are affiliated to the party that had earned the majority of votes in the last municipal elections. ${ }^{4}$ Table 1 presents an overview and description of all of the variables used in the econometric estimations. The table also includes as a summary of the theoretical and empirical literature reviewed in Sect. 2 the expected signs of the coefficients of the explanatory variables.

In order to test whether there is spatial correlation at all, two indicators of spatial correlation, the Moran's I test statistic and the Lagrange Multiplier tests, are used in this paper. Both tests are used to indicate a potential spatial correlation of some variable. For instance, the null hypothesis of Moran's $I$ test statistics assumes that the (neighboring) data is randomly dispersed in space. A rejection of the hypothesis thus indicates a spatial correlation in the data.

Based on the results of these two tests, two models are applied in addition to a standard panel fixed effects regression without taking into consideration the spatial correlation, which serves as a frame of reference. The results of a spatial autoregressive model (SAR), as well as of a spatial error model (SEM) are presented afterward. The spatial auto-regressive model (SAR) takes the following form:

$$
\text { CultSpend }_{i t}=\beta X_{i t}+\rho W \text { CultSpend }_{j t}+\epsilon,
$$

with $i \neq j$, and $X_{i t}$ denoting the vector of explanatory variables (socio-economics, fiscal policy, politics, spatial/regional; see Table 1). $W$ is the spatial weighting matrix, which defines the cut-off point and the spatial weights within the relevant distance, and $\rho$ is the spatial correlation coefficient. $\epsilon$ is the error term.

As the error terms of municipalities $i$ and $j$ may be correlated, this paper also includes the results of a spatial error model (SEM):

\footnotetext{
3 The results of alternative specifications, e.g., defining a neighborhood by using a different cut-off point for relevant travel distances, can be sent by the author upon request. There are, of course, various methods to define spatial weights, e.g., combinations of the proximity of data on the population, or on the mobility between regions (Baicker, 2005).

${ }^{4}$ In addition to the variables presented in Table 1, the year of the respective municipal election was tested in the empirical estimations in order to ascertain a potential political business cycle of municipal cultural spending. As will be discussed below, the results are ambiguous at best. Therefore, such a variable was left out in the empirical estimations presented in this paper.
} 


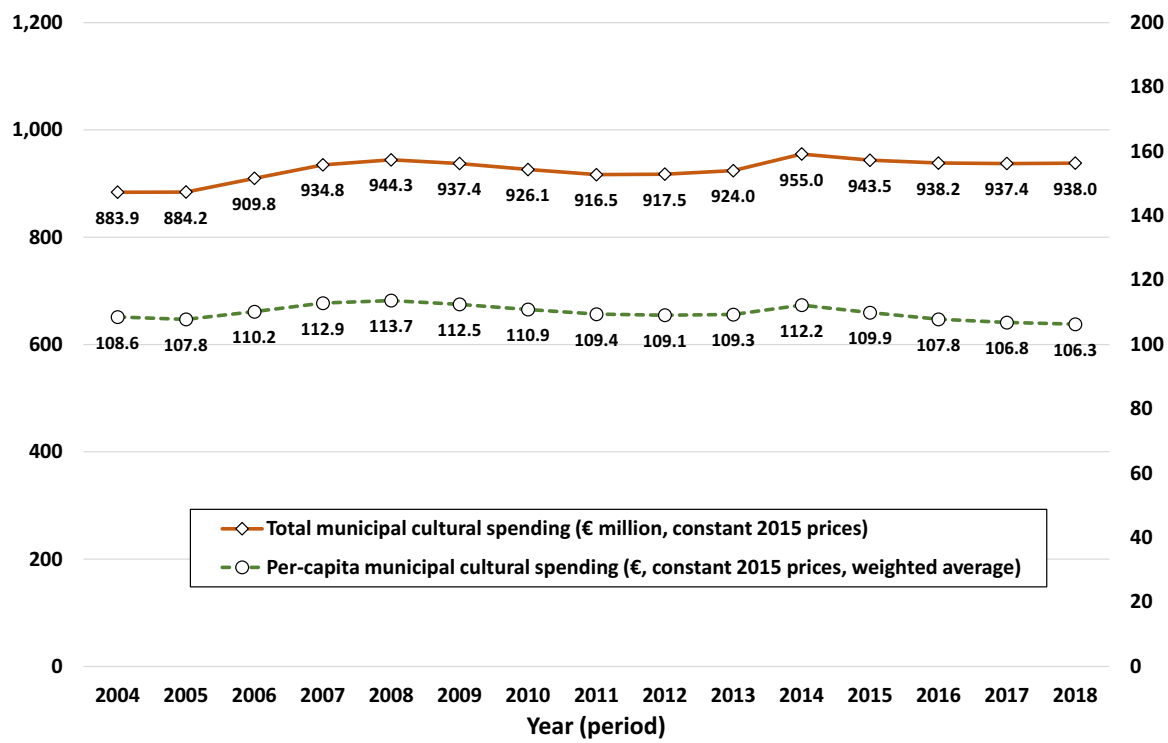

Fig. 1 Municipal cultural spending in Austria (total and per capita, 2004-2018, constant 2015 prices). Source: Own draft and calculations based on Statistics Austria (2020) and GemBon (2019)

$$
\text { CultSpend }_{i t}=\beta X_{i t}+\epsilon \text {, }
$$

with $\epsilon=\lambda W \epsilon+u$.

In the following, a short presentation of the descriptive results follows in Sect. 4, while all econometric estimations (including those with/without spatial dependence) are presented in Sect. 5 .

\section{The descriptive results: total and per-capita cultural spending}

As briefly discussed in the introduction, Austrian municipalities spend about one third of all public cultural expenditure for cultural affairs. One third is spent by the national government, the rest by the provincial (regional) governments. In total, the municipalities spent $€ 938$ million in 2018 (constant 2015 prices), an amount that, in total, increased by $6.13 \%$ from 2004 to 2018 (the average annual increase was about $0.4 \%$ ). (After subtracting the cultural spending of Vienna, which is not only the Capital City of Austria, but also a federal province in its own right, municipal cultural spending amounted to $€ 650$ million, which corresponds to $€ 93$ per capita.)

The weighted average of the municipal cultural spending (all Austrian municipalities including Vienna) amounted to $€ 106$ per capita in 2018, which is a slight reduction of per-capita spending from $€ 108$ in 2004. While the total municipal spending for cultural affairs increased, the population of Austria grew as well; therefore, the per-capita spending remained almost constant over the observation period. The municipal cultural spending in Austria over a period of time is presented 


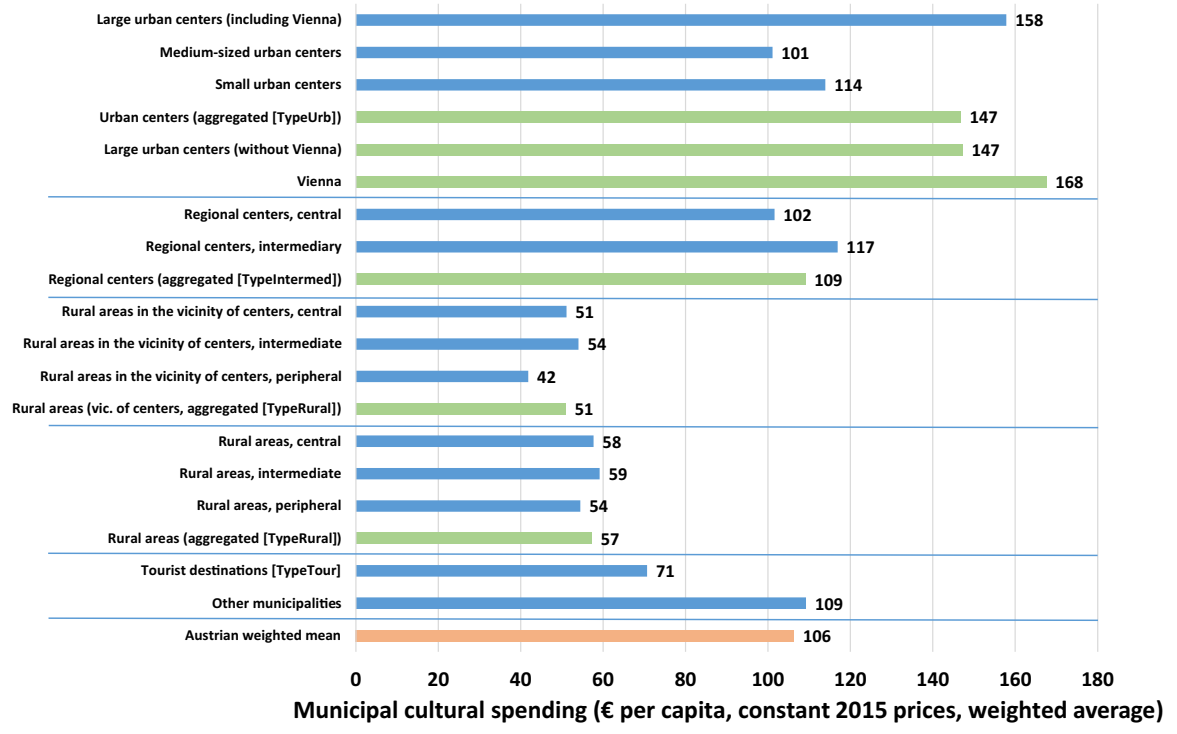

Fig. 2 Municipal cultural spending (€ per capita, constant 2015 prices, weighted average ${ }^{a}$ ) according to the urban-rural typology of municipalities. ${ }^{a}$ In order to compute mean values (within the different population classes), the observations are weighted by the population size of each municipality. Source: Own draft and calculations based on Statistics Austria (2020) and GemBon (2019)

in Fig. 1. It is noteworthy that during the observation period from 2004 to 2018, municipal spending increased until the financial and economic crisis in 2008, and afterward was slightly reduced before it increased again until 2014.

The municipal cultural spending differs very much in the various types of municipalities. For instance, some larger cities and regional centers spend more than $€ 300$ per capita a year, while smaller municipalities spend as low as $€ 1$ per resident a year.

In regard to the urban-rural typology of municipalities, the average municipal spending for cultural affairs is displayed in Fig. 2. Municipalities classified as 'urban' clearly exhibit the highest cultural expenditures annually with, on average, about $€ 147$ per capita. Vienna's spending as a Capital City and as a federal province is the highest annually, with about $€ 168$ per capita. The results of Fig. 2 also infer that rural areas spend annually about $€ 51-€ 57$ per capita, which is much less than urban and intermediate municipalities.

While the classification of municipalities as 'urban' or 'rural' seems to be important for analyzing cultural spending, the size of each municipality is in most cases, but not necessarily so, correlated with the categories of this typology. There are certainly some smaller municipalities classified as 'urban,' as well as some larger municipalities in rural and peripheral regions. The smaller municipalities do indeed spend less than larger ones (see Fig. 3). The municipalities with up to 5000 residents spend annually about $€ 44-€ 61$ per capita in a clear $U$-shaped pattern. This correlation may be due to economies of scale in this group of municipalities. However, with a larger population, municipalities spend even more per citizen, up to $€ 168$ for cities with a population over 50,000. (There are only nine cities in Austria that 


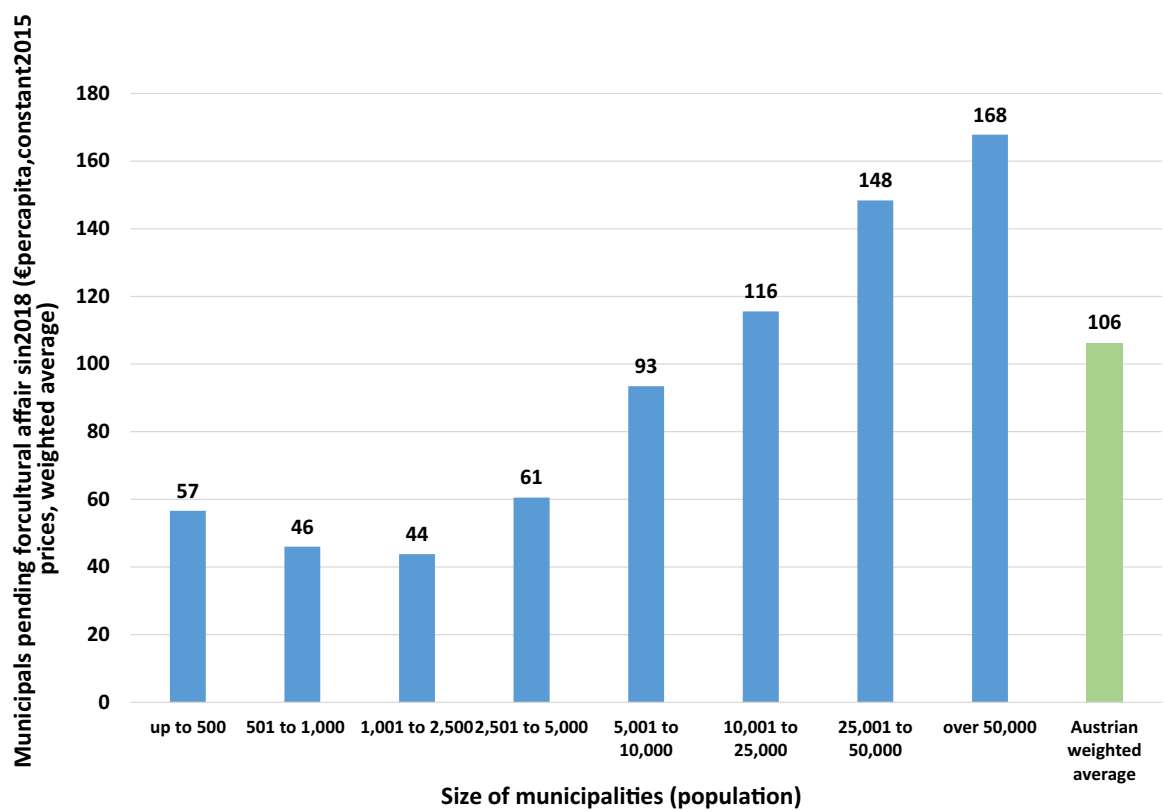

Fig. 3 Municipal spending for cultural affairs in 2018 ( $€$ per capita, constant 2015 prices, weighted average $^{\mathrm{a}}$ ). ${ }^{\mathrm{a}}$ In order to compute mean values (within the different population classes), the observations are weighted by the population size of each municipality. Source: Own draft and calculations based on Statistics Austria (2020) and GemBon (2019)

fall into this category.) The larger municipalities and cities provide a wide range of goods and services to the surrounding regions, and to the nation as a whole, and therefore exhibit much higher expenditures for several categories of infrastructures and public services, including those for cultural affairs (cf., Mitterer et al., 2016).

This brief descriptive analysis shows that there are various factors that are likely to determine municipal cultural spending, such as the size of the municipality, and the location and type (e.g., urban, rural) connected to socio-economic, fiscal, political, and spatial characteristics. Thus, the next section describes the econometric results in regard to these determinants.

\section{The econometric results: the determinants of municipal cultural spending}

\subsection{Fixed-effects panel estimations}

A first insight into the determinants of municipal cultural spending is provided by Table $2 .^{5}$ The estimations of a standard fixed-effects panel model (with

\footnotetext{
${ }^{5}$ The econometric estimations were carried out by using the econometric packages EViews 11 and $\mathrm{R}(\mathrm{R}$ Core Team, 2020).
} 


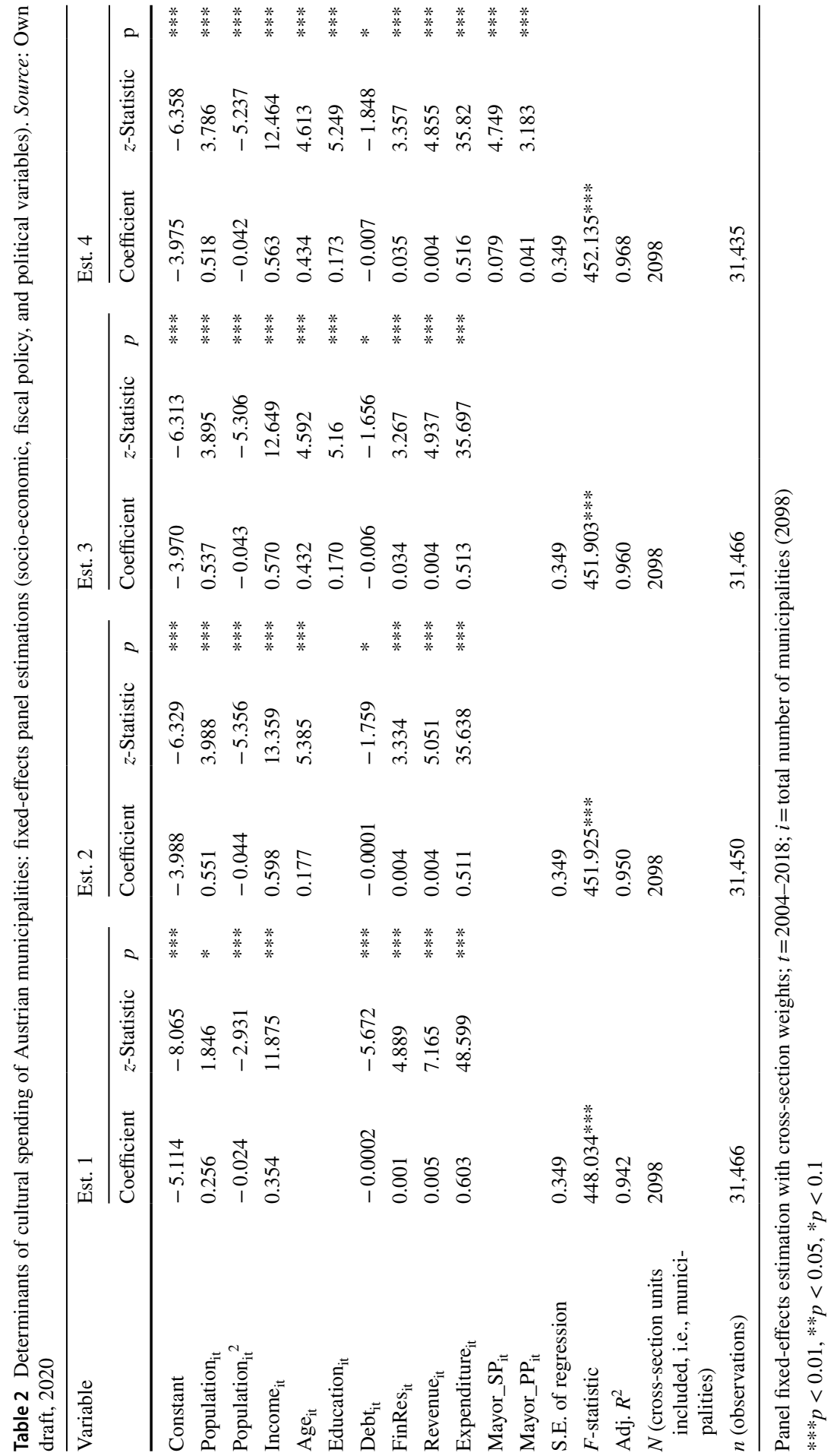


cross-section weights) infer that a range of variables determines municipal cultural spending. First of all, the Est. 1 includes a basic estimation with selected population and public finance variables. As already shown in Sect. 4, cultural spending might increase with the size of the municipality (city). The functional specification with a quadratic term is based on the assumption that a larger population may lead to increased spending, but that the increase rates are diminishing. This might be owing to the provision of cultural goods and services to the surrounding regions made by cities (spillover effects), and economies of scale. The average household income in a municipality also seems to be positively correlated with the cultural spending: The municipalities, where households with above-average income live, spend more on cultural affairs.

As can be expected from the review of empirical studies (Sect. 2), the financial distress and the economic resources of municipalities may also influence their cultural spending. With higher public debt and less financial resources available (measured by the cash-flow of municipalities, and the municipalities' own payroll taxes), the municipal cultural spending decreases. The size of the municipal budget, measured by the municipalities' total revenues (reduced by investments and debt service), also influences the cultural spending.

Est. 1 results in a rather high explanatory power of over $95 \%\left(\operatorname{adj} . R^{2}\right)$, which may be expected from a panel time series analysis of this kind. The results of the estimation clearly conform to a number of theoretical expectations. For instance, an aboveaverage income of households is correlated with higher cultural expenditure.

This basic model is extended in Est. 2 that includes the age of the population as an additional covariate. The age variable measures the share of residents aged 45 years or older. The results of Est. 2 show that the significance, the sign and the size of the coefficients of the explanatory variables do not change substantially. The results infer that the municipalities with an older population afford aboveaverage cultural expenditures.

Est. 3 includes the education levels as the share of residents who hold at least a high-school degree. The municipalities with larger shares of well-educated residents also afford a higher spending for cultural affairs.

Finally, Est. 4 infers that municipalities run by social democratic mayors or conservatives afford higher cultural spending than those with mayors of other parties. Interestingly, the municipalities run by social democrats spend most on cultural affairs. The coefficients of the party affiliation are significantly different. However, mayors of major parties (social democrats, conservatives) both spend significantly higher amounts on cultural affairs than mayors of other parties or without a party affiliation (baseline).

The urban-rural typology described above was also tested in this framework of a fixed-effects panel estimation with cross-section weights. It appears that the typology is too closely correlated with the size of the municipality (population), average income of households, and the mayor's party affiliation. As outlined above, the size of the municipality, and the category of urban and regional centers, are narrowly linked. The cities in Austria are mostly run by social democrats (and therefore, there might be some multicollinearity between the size of the municipality and the party affiliation of the mayor); this result is further discussed in the conclusions. Using the 
Table 3 Tests of the spatial correlation of municipal cultural spending (Variable: CultSpend ${ }_{\mathrm{it}}$ ) depending on selected weight matrices (distances of 15,30 , and $45 \mathrm{~min}$ assumed). Source: Own draft, 2020

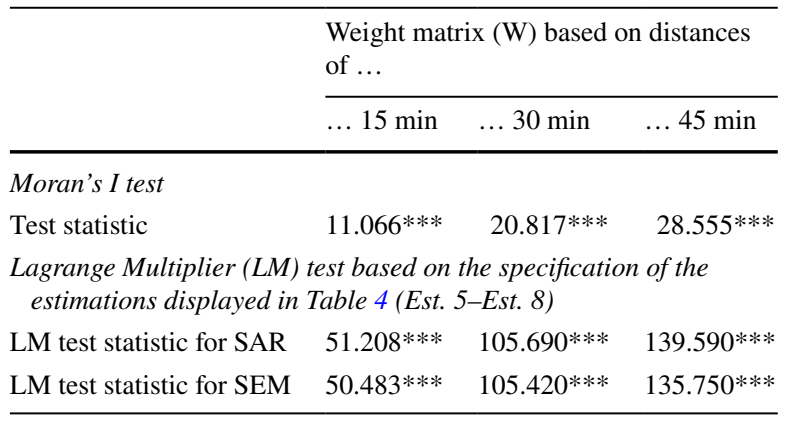

$\mathrm{H}_{0}$ : No spatial correlation between the neighboring municipalities' cultural spending (variable CultSpend $\mathrm{i}_{\mathrm{it}}$ ); $* * * p<0.01$

$t=2004-2018 ; i=$ total number of municipalities (2098)

urban-rural typology in this context therefore does not add more explanatory power to the models. The chosen variables (e.g., population and income variables) are better predictors of municipal cultural spending.

\subsection{Spatial autoregression and error estimations}

In order to account for the possible spatial autocorrelation (i.e., that the cultural spending of the municipality $A$ may be correlated to the one of the municipality $B$ ), and before presenting the results of the empirical estimations, the Moran's I test statistic as well as the Lagrange Multiplier (LM) diagnostics were computed.

For the purpose of this paper, both statistics test whether the null hypothesis $\left(\mathrm{H}_{0}\right)$ of no spatial correlation should be rejected. As discussed above, the definition of an appropriate weighting matrix in order to define 'neighboring' municipalities is of crucial importance. As there is no clear-cut standard definition, Table 3 presents the test statistics and levels of significance for the Moran's spatial auto-regression and the LM tests, based on different assumptions about the relevant distance from municipality $A$ to municipality $B$. It can be inferred from the results of the Moran's $I$ statistics that the municipal cultural spending is indeed spatially correlated. The results of the LM test also confirm that the observations of neighboring municipalities are spatially correlated (Table 3 ). Both test statistics clearly reject the null hypothesis $\left(\mathrm{H}_{0}\right)$ of no spatial correlation.

The spatial estimation results based on the same specification of the explanatory variables as in Table 2 (Est. 4) are presented in Table 4. The estimations account for the spatial autoregression in the framework of a spatial autoregressive model (SAR; see Eq. (1) in Sect. 3) and a spatial error model (SEM, see Eq. (2)). ${ }^{6}$ A

\footnotetext{
6 The results of different weight matrices and of different model specifications are available from the author upon request. In particular, the results of spatial distribution models (SDM, with spatially lagged explanatory and dependent variables) and spatial Durbin error models (SDEM, with spatially lagged explanatory variables and errors) are not presented owing to the lack of space. An inspection of the results of these models, however, does not lead to substantially different conclusions in regard to the size or significance of the estimated coefficients in comparison to the models presented in this paper.
} 


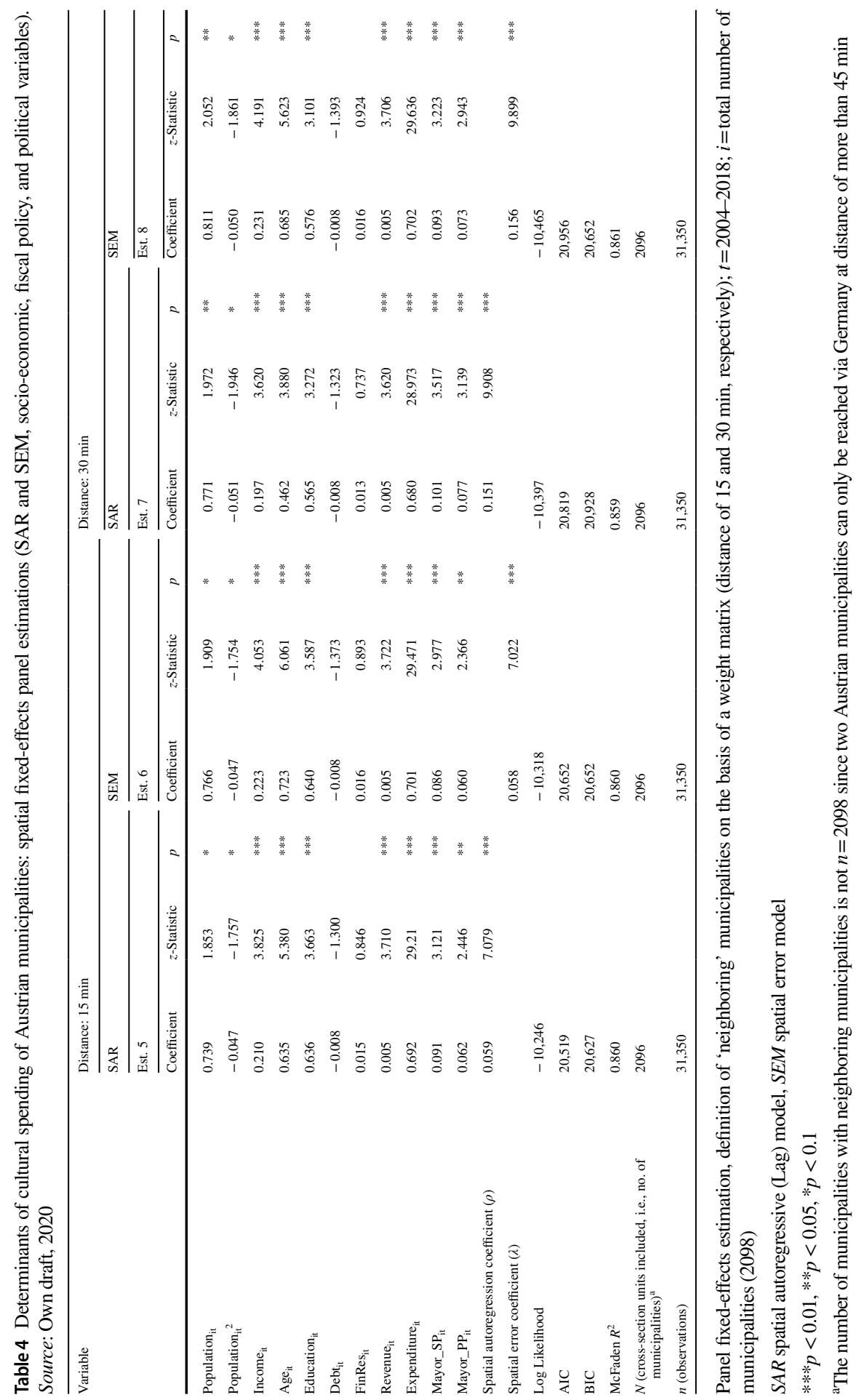


comparison between the results of the standard fixed-effects panel model, and the spatially weighted estimations, reveals that the size of the coefficients of the estimations changes after correcting for the spatial interdependence. Owing to the lack of space, only the estimations based on a weighting matrix for defining the "neighboring' municipalities within a distance of 15 and $30 \mathrm{~min}$ were presented. (The results for different assumptions about the relevant distances, for instance, $45 \mathrm{~min}$, can be obtained from the author upon request.)

In general, the estimations (SAR, SEM) revealed a rather small spatial correlation of cultural spending of neighboring municipalities. Depending on the chosen distance of neighboring municipalities, a $10 \%$ increase of the neighboring municipalities' cultural spending only leads to a $0.6-1.5 \%$ increase of cultural spending in the respective municipality. This influence is also small in comparison to the other explanatory variables (standardized coefficients), for instance, the size of the municipality (population) or fiscal policies (total expenditures). ${ }^{7}$

The nonlinear (quadratic) influence of the population variable is also visible in the first Est. 5 of Table 4. However, it seems that the spatial correlation between the cultural spending of neighboring municipalities reduces the level of significance of the quadratic term. In comparison to Est. 4 in Table 2, the coefficients of the population variable are also slightly larger in the spatial estimation. The influence of the income variable is comparatively smaller and amounts to 0.21 in Est. 5. However, the coefficient of the income variable is highly significant, similar to the ones of the age and education variables. The municipal cultural spending is therefore significantly and positively correlated with the average income of residents, with their age and their (formal) education. This interesting result will be discussed further in Sect. 6.

Two variables that have shown a significant influence on the municipal cultural spending in the 'standard' fixed-effects panel estimations in Table 2 have lost their influence. While the coefficients still exhibit the expected signs (i.e., a negative sign for the debt variable, and a positive sign for the variables measuring the financial resources of the municipality), the inclusion of the spatial correlation of the dependent variable reduces the significance of these variables.

Again, the revenue originating from the municipal payroll tax (revenue variable) as an indicator of the economic development of the municipality is significantly correlated with the municipal cultural spending. The size of the coefficient is close to the one in Est. 4 (Table 2).

Finally, the municipalities governed by mayors affiliated to the social democratic party spend more than the municipalities with mayors from the conservative Austrian People's Party (the baseline is, again, denoted by mayors without a major party affiliation). However, the difference between the two coefficients is smaller than in the estimations discussed above.

\footnotetext{
7 Table 4 shows non-standardized coefficients in order to facilitate an economic interpretation of the elasticity of cultural spending with respect to the explanatory variables. Tables with standardized coefficients are left out owing to the lack of space, but can be sent from the author upon request.
} 
Est. 6 (Table 4) presents the results of a similar SEM (spatial error model), again based on a weighting matrix with a distance of up to $15 \mathrm{~min}$ for defining 'neighboring' municipalities. The size and significance of the respective coefficients remain broadly in the same order of magnitude.

Est. 7 and Est. 8 of Table 4 are the estimations based on the weighting matrix that defines neighboring municipalities as those within a distance of $30 \mathrm{~min}$. Again, the results are not substantially different to those discussed above, except for an increased level of significance - in particular-for the population and the political variables. In regard to the statistical fit of these estimations, the spatial models exhibit a McFadden- $R^{2}$ of about 0.86 .

\section{Discussion, summary and conclusions}

The cultural policies in a (mildly) federal state, such as Austria, are one of the few policy fields where local authorities have a great deal of leeway for decision-making. Other municipal tasks, e.g., public schools, roads, waste management and water provision, are mandatory municipal tasks for which the municipalities are funded either by their respective shares of tax revenues to be shared among the various levels of government (national, provincial, and local), or by local utility fees. Local taxes levied by municipalities, in addition to utility fees, amount to about $25 \%$ of total municipal budgets.

As the municipal policies in the cultural sector are not mandatory (statutory) municipal tasks, and are also not regulated in detail (except for the general provisions in regard to public decision-making and utilizing public funds), the municipalities are rather autonomous in regard to the extent to which municipal cultural affairs are funded. Examples of the municipal cultural policies include the operation and funding of local cultural centers for events, such as concerts and exhibitions, the financial support for local cultural associations, and the management and support of Schools of Music.

The municipal cultural policies therefore have to be financed mainly out of the municipalities' cash-flow (financial resources not currently devoted to other policy fields). The municipal cultural spending can be explained surprisingly well by a limited number of socio-economic and political variables, together with various spatial components. First of all, the size of the municipality determines the cultural expenditure. The larger municipalities increase per-capita cultural spending, and therefore seem to provide cultural goods and services not only to their own constituents, but to a larger audience in the surrounding region. However, the linkages between the municipal cultural spending and the size of the municipality measured by the population are not only linear but quadratic. This result infers that economies of scale, density and, eventually, scope, reduce the marginal costs of cultural goods and services in larger municipalities (towns, cities). 
Moreover, the socio-economic characteristics of citizens-income, age, education-are important factors that apparently influence the municipal spending on cultural affairs. Interestingly, the income and age variables have not been found to be as influential in other studies dealing with revealed preferences for cultural infrastructures. Getzner (2020a) noted that cultural participation (i.e., the principal attendance at cultural events at least once a year) of citizens with a higher income increases, but that cultural consumption (i.e., the frequency of attending cultural events) decreases with a higher income owing to the higher opportunity costs of leisure time. The linkages estimated in the studies on revealed preferences between the cultural participation/consumption and the income of citizens is thus not as straightforward as this paper might infer. Rather, the clear positive correlation between the municipal cultural spending and the average income of citizens is indicated by the econometric results.

However, the cultural participation and cultural consumption show a negative correlation with age. Younger citizens consume more cultural goods and services. This result of Getzner (2020a) may contradict the findings of this paper, which infer that the municipal cultural expenditure increases with the higher average age of the citizens. This could be an indicator of the political economy of municipal cultural policy if the turnout by older voters is higher, or if municipal policy makers place less emphasis on cultural preferences of younger citizens. Furthermore, this result could also indicate that some cultural institutions frequented by older audiences may also be those with higher investment and operating costs (e.g., theaters and art museums compared to music clubs and cinemas).

The estimations of this paper also provide evidence of the influence of municipal fiscal policy framework on cultural spending. In particular, the cash-flow of municipalities, the revenues of the municipal payroll tax, and the levels of municipal (public) debt are correlated with the municipal spending for cultural affairs.

Finally, the results of this paper also infer that political ideologies may influence the municipal spending for cultural affairs. The empirical estimations show that the municipalities governed by a mayor affiliated to the social democratic party spend more on culture. While one could argue that the larger cities in Austria are mostly governed by social democrats, this correlation seems to provide support for the general notion of higher public expenditure in these municipalities. There might be several reasons for this result, which seems to be at odds with other studies. On the one hand, it was argued that right-wing governments may favor policies that benefit their (presumably high-income) electorate, while left-wing governments may replace cultural spending with wealth-redistributing policies, such as social housing (cf. Benito et al., 2013). On the other hand, left-wing governments are said to favor active government interventions and larger public budgets (cf. Bastida et al., 2013; Haber \& Neck, 2006). However, the estimations of this paper include variables that already control for the size of the municipality. Therefore, the political ideology of the leading party that nominates the mayor seems to influence cultural policies in addition to 
the size of the municipality. ${ }^{8}$ However, a further exploration of a potential political business cycle of municipal cultural spending by including a variable denoting the year of the municipal elections did not turn out to be successful. Other papers (e.g., Sanjuán et al., 2020) suggested that a political cycle of cultural spending might be significant owing to the autonomy of decision makers in municipal cultural policies. For the Austrian context-as has been the case in other studies on municipal fiscal policies (e.g., Bröthaler et al., 2015)—a political cycle of cultural spending cannot be proven.

These results all have to be considered in the light of the spatial dependence investigated in this paper by means of spatial autoregressive and spatial error models. Both models infer that there is a significant spatial correlation between the cultural spending of neighboring municipalities. This corroborates the results of other papers, such as the ones by Costa et al. (2015) and López et al. (2017). However, the significant but rather small coefficients of the spatial auto-regression indicators $(\rho, \lambda)$ infer that the cultural spending of municipality $i$ is not heavily determined by the spending of its neighboring municipalities. Within a travel distance of $15 \mathrm{~min}$, a $10 \%$ increase in the neighboring municipalities' spending increases the municipality $i$ 's average cultural spending by about only $0.6 \%$. Taking a broader definition of the neighboring municipalities within a range of $30 \mathrm{~min}$, a $10 \%$ increase of the neighboring municipalities' spending results in a $1.5 \%$ increase of the spending of municipality $i$. In regard to the spatial determinants of municipal cultural spending, the size of municipalities discussed above, and fiscal policy variables (such as total per capita municipal spending) seems to have a much larger effect than spatial interlinkages. This conclusion can be drawn on the basis of the standardized coefficients included in the estimations. While it can be inferred from the empirical results that the spatial correlation of cultural expenditure of neighboring municipalities are small, the different reasons for such correlation could not be disentangled in this paper. In the theoretical section of this paper (Sect. 2), several reasons for positive and negative correlations were presented (e.g., the provisioning function of larger cities; free-riding of smaller municipalities in metro-regions; yardstick competition). These different reasons might be present at the same time, and might also mutually cancel each other. With the empirical approach chosen in this paper, the contribution of each of these factors could not be ascertained.

Based on the estimations of this paper, there are several policy conclusions to be drawn. Firstly, municipalities are indeed rather autonomous in their cultural policy decisions, and are also restricted by their financial resources. Their cultural spending seems to be determined by socio-economic characteristics of their electorate, and by the size of their population. Secondly, co-operation between municipalities, or other arguments of spatial dependencies (e.g., yardstick competition), do not appear to be

\footnotetext{
${ }^{8}$ Historically, the period of the 'Red Vienna' (1919-1934) was a period of social democratic governments in the Austrian capital city. Besides many innovative policies, such as municipal and social housing, and a wide range of social services, special emphasis was laid on public education and cultural affairs (e.g., libraries, theaters). The local policies in Vienna specifically aimed at educating citizens and enabling them to participate in societal and democratic processes, as well as to enjoy a wide variety of cultural events. From this viewpoint, social democratic governments may well decide to increase the public cultural expenditures (Schwarz et al., 2019).
} 
of major importance since spatial dependence - taking all arguments together-is rather limited. Decisions seem to be made rather independently. This is a quite unexpected result, given the fact that there is much collaboration between municipalities in other infrastructure policy fields (e.g., water and wastewater management, road infrastructure, public transport, sports infrastructures, such as indoor swimming pools). The results of the lack of co-operation can also be observed, for instance, by budgetary problems associated with municipal cultural centers, which often have a relatively low cost-recovery ratio (cf. Biwald et al., 2020). In addition, many larger municipalities (cities) provide cultural goods and services to the whole region. One major policy recommendation of this paper is therefore to improve local and regional co-operation in the fields of cultural policies in order to provide more efficient cultural infrastructures to citizens, and to use cultural funds more effectively.

Acknowledgements The author thanks the anonymous reviewers who provided many helpful suggestions for substantial improvements of the paper. Many thanks are also due to J. Bröthaler for providing the spending data of Austrian municipalities, L. Rücker for research assistance on politico-economic variables, and T. Neuhuber for substantial support for setting up the scripts of the empirical estimations in R. All errors are, of course, the responsibility of the author.

Funding Open access funding provided by TU Wien (TUW).

\section{Declarations}

Conflict of interest The author declares that there is no conflict of interest.

Open Access This article is licensed under a Creative Commons Attribution 4.0 International License, which permits use, sharing, adaptation, distribution and reproduction in any medium or format, as long as you give appropriate credit to the original author(s) and the source, provide a link to the Creative Commons licence, and indicate if changes were made. The images or other third party material in this article are included in the article's Creative Commons licence, unless indicated otherwise in a credit line to the material. If material is not included in the article's Creative Commons licence and your intended use is not permitted by statutory regulation or exceeds the permitted use, you will need to obtain permission directly from the copyright holder. To view a copy of this licence, visit http://creativecommons.org/licen ses/by/4.0/.

\section{References}

Baicker, K. (2005). The spillover effects of state spending. Journal of Public Economics, 89, 529-544.

Bastida, F., Guillamón, M.-D., \& Benito, B. (2013). Municipal spending in Spain: Spatial approach. Journal of Urban Planning and Development, 139(2), 79-93.

Bel, G., \& Warner, M. E. (2015). Inter-municipal cooperation and costs: Expectations and evidence. Public Administration, 93, 52-67.

Benito, B., Bastida, F., \& Vicente, C. (2013). Municipal elections and cultural expenditure. Journal of Cultural Economics, 37, 3-32.

Bertacchini, E., \& Dalle Nogare, C. (2014). Public provision versus outsourcing of cultural services: Evidence from Italian cities. European Journal of Political Economy, 35, 168-182.

Biwald, P., Mitterer, K., \& Seisenbacher, M. (2020). Österreichische Gemeindefinanzen 2020: Entwicklungen 2009 bis 2023. Österreichischer Städtebund/kdz.

Bröthaler, J., \& Getzner, M. (2011). Fiscal autonomy and total government expenditure: An Austrian case-study. International Advances of Economic Research, 17, 134-156. 
Bröthaler, J., Getzner, M., \& Haber, G. (2015). Sustainability of local government debt: A case study of Austrian municipalities. Empirica, 42, 521-546.

Buettner, T., \& Janeba, E. (2016). City competition for the creative class. Journal of Cultural Economics, 40, 413-451.

Case, A. C., \& Rosen, H. S. (1993). Budget spillovers and fiscal policy interdependence. Journal of Public Economics, 52, 285-307.

Cheng, S.-W. (2006). Cultural goods creation, cultural capital formation, provision of cultural services and cultural atmosphere accumulation. Journal of Cultural Economics, 30, 263-286.

Compendium. (2021). Data on cultural policies and spending. Compendium of Cultural Policies \& Trends.

Costa, H., Gonçalves, L. V., \& Portela, M. (2015). Interactions in local governments' spend-ing decisions: Evidence from Portugal. Regional Studies, 49, 1441-1456.

Dalle Nogare, Ch., \& Galizzi, M. M. (2011). The political economy of cultural spending: Evidence from Italian cities. Journal of Cultural Economics, 35, 203-231.

Di Liddo, G., \& Giuranno, M. G. (2016). Asymmetric yardstick competition and municipal cooperation. Economics Letters, 14, 64-66.

Feder, T., \& Katz-Gerro, T. (2012). Who benefits from public funding of the performing arts? Comparing the art provision and the hegemony-distinction approaches. Poetics-Journal of Empirical Research on Culture the Media and the Arts, 40(3), 359-381.

Frère, Q., Leprince, M., \& Paty, S. (2014). The impact of intermunicipal cooperation on local public spending. Urban Studies, 51, 1741-1760.

Frey, B. S. (1999). State support and creativity in the arts: Some new considerations. Journal of Cultural Economics, 23(1), 71-85.

Gebremariam, G. H., Gebremedhin, T. G., \& Schaeffer, P. V. (2012). County-level determinants of local public services in Appalachia: A multivariate spatial autoregressive model approach. The Annals of Regional Science, 49, 175-190.

GemBon, (2019). Information and analysis system of assessing the credit ratings of the Austrian municipalities, based on data of municipal financial statistics. Database and software of the Department of Public Finance and Infrastructure Policy (Institute of Spatial Planning), Version 2.9 (J. Bröthaler); Vienna University of Technology (TU Wien). Vienna.

Getzner, M. (2004). Cultural policies and fiscal federalism. Public Finance and Management, 4(1), 21-50.

Getzner, M. (2015). Cultural politics: Exploring determinants of cultural expenditure. Poetics-Journal of Empirical Research on Culture, the Media and the Arts, 49(2), 60-75.

Getzner, M. (2020a). Spatially disaggregated cultural consumption: Empirical evidence for cultural sustainability from Austria. Sustainability, 12, 10023.

Getzner, M. (2020b). Urban and rural preferences for cultural policies and infrastructures. Cultural Trends, 29, 378-399.

Getzner, M., \& Bröthaler, J. (2019). Exkurs: Regionale Kultureinrichtungen und -ausgaben in Österreich. In M. Böning \& E. Lutz (Eds.), Werte(De)Konstruktionen: Die Problematik starker Orientierungen (pp. 368-387). De Gruyter.

Haber, G., \& Neck, R. (2006). Sustainability of Austrian public debt: A political economy perspective. Empirica, 33, 141-154.

Hasitschka, W. (2018). Kulturbetriebslehre: Zur Dialektik von Kultur und Organisation. Löcker.

Kirchberg, V., \& Kuchar, R. (2014). States of comparability: A meta-study of representative population surveys and studies on cultural consumption. Poetics, 43, 172-191.

López, F. A., Martínez-Ortiz, P. J., \& Cegarra-Navarro, J.-G. (2017). Spatial spillovers in public expenditure on a municipal level in Spain. The Annals of Regional Science, 58, 39-65.

Lucas, J., \& McGregor, R. M. (2020). Are city elections unique? Perceptions of electoral cleavages and social sorting across levels of government. Electoral Studies, 66, 102165.

Lundberg, J. (2006). Spatial interaction model of spillovers from locally provided public services. Regionals Studies, 40, 631-644.

Mitterer, K., Bröthaler, J., Getzner, M., \& Kramar, H. (2016). Zur Berücksichtigung regionaler Versorgungsfunktionen von Gemeinden in einem aufgabenorientierten Finanzausgleich Österreichs. Das Öffentliche Haushaltswesen (ÖHW), 57(4), 45-65.

Noonan, D. S. (2015). Arts of the states in crisis: Revisiting determinants of state-level appropriations to arts agencies. Poetics-Journal of Empirical Research on Culture, the Media and the Arts, 49(1), $30-42$. 
Peacock, A., \& Scott, A. (2000). The curious attraction of wagner's law. Public Choice, 102, 1-17.

Potrafke, N. (2011). Public expenditures on education and cultural affairs in the West German states: Does government ideology influence the budget composition? German Economic Review, 12, 124-145.

R Core Team. (2020). R: A language and environment for statistical computing. R Foundation for Statistical Computing (www.R-project.org).

Richards, G. (2018). Cultural tourism: A review of recent research and trends. Journal of Hospitality and Tourism Management, 36, 12-21.

Rössel, J., \& Weingartner, S. (2015). Nothing but the cuckoo clock? Determinants of public funding of culture in Switzerland, 1977-2010. Poetics-Journal of Empirical Research on Culture, the Media and the Arts, 49(1), 43-59.

Sanjuán, J., Rausell, P., Coll, V., \& Abeledo, R. (2020). Mayors, using cultural expenditure in an opportunistic way improves the chances of re-election, but do not do it: Revisiting political budget cycles. Sustainability, 12, 9095.

Schulze, G., \& Rose, A. (1998). Public orchestra funding in Germany: An empirical investigation. Journal of Cultural Economics, 22, 227-247.

Schwarz, W. M., Spitaler, G., \& Wikidal, E. (Eds.). (2019). Das Rote Wien 1919-1934: Ideen, Debatten, Praxis. Wien Museum.

Seaman, B. (2006). Empirical studies of demand for the performing arts. In V. A. Ginsburgh \& D. Throsby (Eds.), Handbook of the economics of art and culture (Vol. 1, pp. 415-472). North Holland.

Štàstná, L. (2009). Spatial interdependence of local public expenditures: Selected evidence from the Czech Republic. AUCO Czech Economic Review, 3, 7-25.

Statistics Austria, (2020). Data on cultural spending, income, population. Statistik Austria, (www.stati stik.at).

Tröndle, M., \& Steigerwald, C. (2019). Geschichte, Funktionen und Diskurse der Kulturpolitik(forschung). In M. Tröndle \& C. Steigerwald (Eds.), Anthologie Kulturpolitik [Anthology of cultural policy] (pp. 15-44). Transcript Verlag.

Wagner, A. (1958). Three extracts on public finance. In R. A. Musgrave \& A. T. Peacock (Eds.), Classics in the theory of public finance (pp. 1-15). Palgrave Macmillan.

Werck, K., Heyndels, B., \& Geys, B. (2008). The impact of 'central places' on spatial spending patterns: Evidence from Flemish local government cultural expenditures. Journal of Cultural Economics, 32, 35-58.

Zembylas, T. (2004). Kulturbetriebslehre: Grundlagen einer Inter-Disziplin. VS Verlag für Sozialwissenschaften.

Zembylas, T., \& Mokre, M. (2003). Sein oder Nichtsein: Vielfalts- und Partizipationsförderung als Leitziele einer künftigen Kulturpolitik. Kurswechsel, 22(4), 47-61.

Publisher's Note Springer Nature remains neutral with regard to jurisdictional claims in published maps and institutional affiliations. 